\title{
Relação entre Níveis de Inóculo de Colletotrichum gossypii var. cephalosporioides nas Sementes e o Progresso da Ramulose do Algodoeiro*
}

\author{
Dejânia V. Araújo, Edson A. Pozza, José C. Machado, Elisandra B. Zambenedetti, Enia M. Carvalho \\ \& Fabiane A. O. Celano
}
Departamento de Fitopatologia, Universidade Federal de Lavras, Cx. Postal 3037, CEP 37200-000, Lavras, MG, e-mail: eapozza@ufla.br

(Aceito para publicação em 20/01/2006)

Autor para correspondência: Edson A. Pozza

ARAÚJO, D.V., POZZA, E.A., MACHADO, J.C., ZAMBENEDETTI, E.B., CARVALHO, E.M. \& CELANO, F.A.O. Relação entre níveis de inóculo de Colletotrichum gossypii var. cephalosporioides nas sementes e o progresso da ramulose do algodoeiro. Fitopatologia Brasileira 31:147-151. 2006.

\begin{abstract}
RESUMO
O objetivo do trabalho foi estudar a relação entre porcentagens de sementes de algodoeiro infectadas com Colletotrichum gossypii var. cephalosporioides e o progresso da ramulose no campo. O experimento foi conduzido em blocos ao acaso com cinco tratamentos e três repetições. Os tratamentos foram compostos por parcelas contendo 0 , 4, 8 e 16\% de sementes infectadas com o patógeno. Avaliou-se a germinação e a população final aos dez e 30 dias após a semeadura, respectivamente. As avaliações da incidência e da severidade da ramulose foram feitas, semanalmente, a partir de 30 dias até 95 dias após a semeadura e os dados transformados para área abaixo da curva de progresso da incidência (AACPI) e da severidade (AACPS) da doença. Ao final do experimento avaliou-se a produção de algodão em caroço (Kg/ha) e a transmissibilidade do patógeno planta-semente. Não houve diferença significativa, entre os tratamentos, para a germinação, a população final e a produção. A AACPI, AACPS da doença e a transmissão do patógeno planta-semente foram maiores com aumento do inóculo inicial nas sementes, havendo correlação significativa e positiva entre o inóculo inicial e a incidência, bem como, entre o inóculo inicial e a porcentagem da semente coberta com propágulos do patógeno (PSCPP). Da mesma forma, a PSCPP correlacionou-se positivamente com a AACPS.
\end{abstract}

Palavras-chave adicionais: Gossypium hirsutum, inoculação de sementes, ramulose, transmissibilidade.

\begin{abstract}
Relationship between inoculum levels of Colletotrichum gossypii var. cephalosporioides in seeds and the progress of cotton ramulosis

The objective of this study was to verify the relationship between percentage of cotton seeds infected by Colletotrichum gossypii var. cephalosporioides and the progress of ramulosis in the field. The experiment was carried out in Lavras (Minas Gerais State, Brazil) and was designed in randomized blocks with five treatments and replicated three times. The treatments consisted of plots with $0,4,8$ and $16 \%$ of seeds infected with the pathogen. Germination and final stand were evaluated ten and 30 days after sowing. The incidence and disease severity were evaluated, weekly, from 30 to 95 days after sowing and the data were transformed to area under the disease progress curve of the incidence (AUDPCI) and of the severity (AUDPCS). Production ( $\mathrm{Kg} / \mathrm{ha}$ ) and the transmissibility of the pathogen plant-seed were also evaluated. No significant difference was observed for the germination, the final stand and the production. On the other hand, inoculum levels in seeds influenced the AUDPCI and the AUDPCS, and the disease's progress increased with the rise of initial inoculum in seeds. There was positive and significant correlation between both AUDPCS and the percentage of the pathogen on seeds and also between both initial inoculum potential and incidence and percentage of the pathogen on seeds. In the same way, the percentage of the pathogen on seeds was correlated positively to AUDPCS.
\end{abstract}

Additional keywords: Gossypium hirsutum, seed inoculation, ramulosis, transmissibility.

\section{INTRODUÇ̃̃O}

A ramulose do algodoeiro tem como agente etiológico Colletotrichum gossypii South var. cephalosporioides

\footnotetext{
*Parte da Dissertação de Mestrado do primeiro autor. Universidade Federal de Lavras. 2004.
}

A.S. Costa. Esse patógeno é considerado um dos mais importantes para a cultura (Lima et al., 1985). Juntamente com o tombamento de plântulas, é responsável por reduzir a população de plantas no campo, elevar os custos de produção e causar perdas consideráveis (Pozza \& Juliatti, 1994).

O patógeno é transmitido por sementes contaminadas e/ou infectadas, representando risco de introdução em áreas 
onde o patógeno ainda não foi introduzido (Lima et al., 1985). As sementes portadoras do patógeno constituem a principal fonte de inóculo e as lesões de plantas infectadas representam importante fonte de inóculo secundário. Dependendo das condições ambientais, a ramulose pode causar epidemia devido à disseminação do patógeno ser favorecida por respingos de chuva e ventos (Kimati, 1980).

A produção de sementes com qualidade superior requer a adoção de medidas gerais de monitoramento e controle atreladas a um programa rigoroso de inspeção, ainda nos campos de produção de sementes. Para se estabelecer padrões de tolerância em programas de certificação de sementes é necessário desenvolver métodos rotineiros de deteç̧ão de patógenos. Além disso, outros pontos, como a taxa de transmissão pela semente, o mecanismo de transmissão e a relação patógeno-hospedeiro-ambiente precisam ser esclarecidos pela pesquisa e, dessa forma, servir como referência para estabelecer padrões (Tanaka \& Machado, 1985).

Vários trabalhos relataram a transmissibilidade de C. g. var. cephalosporioides por sementes de algodoeiro (Pizzinatto et al., 1991, 1994; Santos et al., 1993; Lima et al., 1985; Tanaka \& Menten, 1992). No entanto, o progresso da doença, utilizando diferentes níveis de inóculo nas sementes, precisa ser melhor elucidado. Diante do exposto, esse trabalho teve por objetivos estudar o progresso da ramulose a partir de sementes com diferentes níveis de $C . g$. var. cephalosporioides, bem como, a transmissibilidade do patógeno planta-semente.

\section{MATERIAL E MÉTODOS}

\section{Área experimental e condução do experimento}

$\mathrm{O}$ experimento foi instalado na área experimental do Departamento de Fitopatologia da Universidade Federal de Lavras, MG. A adubação do solo foi calculada de acordo com os resultados de análise físico-química do solo. O delineamento utilizado foi o de blocos ao acaso, com quatro tratamentos e três repetições, sendo a parcela experimental constituída por seis linhas de $5 \mathrm{~m}$ de comprimento, considerando-se como área útil, as quatro linhas centrais. $\mathrm{O}$ espaçamento utilizado foi de $90 \mathrm{~cm}$ entre linhas e a densidade de semeadura foi de 11 sementes por metro linear, sendo a distância entre tratamentos dentro de um mesmo bloco e entre blocos de 2,0 m.

Os tratamentos testados foram $0 \%, 4 \%, 8 \%$ e $16 \%$ de sementes infectadas com C. g. var. cephalosporioides. Tratos culturais como capinas e controle de pragas foram realizados de acordo com a necessidade da cultura.

\section{Inoculação de sementes}

Sementes da linhagem IAC 01/273, fornecidas pelo Instituto Agronômico de Campinas (IAC) foram previamente deslintadas com ácido sulfúrico (PA) e submetidas à assepsia com hipoclorito de sódio $2 \%$, por um minuto. Posteriormente, as sementes foram inoculadas com o patógeno pelo método de restrição hídrica (Machado et al., 2001). A metodologia constou da adição de um mililitro da suspensão de conídios, na concentração $10^{6}$ conídios $/ \mathrm{mL}$, em placas de petri de $15 \mathrm{~cm}$ de diâmetro, contendo manitol (46,3 g/L) em meio BDA, com potencial hídrico ajustado para -1 MPa, segundo cálculo do software SPPM (Michel \& Radcliffe, 1995). As culturas foram mantidas em incubação à temperatura de $25 \pm 2{ }^{\circ} \mathrm{C}$ e fotoperíodo de $12 \mathrm{~h}$ por três dias, quando as sementes foram colocadas em contato com o fungo, sendo estas, novamente, incubadas por $72 \mathrm{~h}$ nas mesmas condições. Sementes utilizadas como testemunha foram submetidas ao meio com restrição hídrica contendo ágar-água e manitol (-1 MPa) para obter padrão homogêneo de germinação e de emergência em todos os tratamentos.

\section{Emergência em campo, população final, progresso da doença e produção}

A germinação em campo e a população final foram avaliados aos sete e 30 dias após a semeadura, respectivamente. As avaliações da intensidade da doença foram iniciadas aos 30 dias, com intervalo de sete dias até a sexta avaliação e, com intervalo de 15 dias, na sétima e oitava avaliações, quando todas as maçãs já estavam formadas.

Determinou-se, em cada avaliação, a incidência, dada em porcentagem de plântulas infectadas por C. $g$. var. cephalosporioides, e a severidade da ramulose, obtida por meio da escala de notas variando de 0 a 4 , elaborada por Costa (1941), onde: $0=$ Ausência de sintomas; 1 = Lesões necróticas estreladas nas folhas localizadas no ápice da planta; 2 = Encurtamento dos internódios do ápice da planta; 3 = Superbrotamento acentuado, redução no crescimento da planta; $4=$ Planta com superbrotamento e com desenvolvimento comprometido, morte das partes afetadas. Para ponderar a severidade na parcela foi aplicado o índice de McKinney (1923).

A área abaixo da curva de progresso da doença (AACPD) foi obtida com base nos índices de incidência e de severidade, de acordo com Campbell \& Madden (1990). Os tratamentos foram comparados utilizando-se a área abaixo da curva de progresso da incidência (AACPI) e da severidade (AACPS) da ramulose. Para a análise da produção foram colhidos $4 \mathrm{~m}$ de cada parcela, descartando-se $30 \mathrm{~cm}$ de cada lado com objetivo de amenizar o efeito da bordadura. A produção por parcela foi obtida ao pesar o algodão em caroço colhido da área útil e transformando-se $\mathrm{Kg} /$ parcela para $\mathrm{Kg} / \mathrm{ha}$.

\section{Transmissão planta-semente}

A transmissão do patógeno da planta para a semente foi obtida utilizando-se subamostras de cada repetição de todos os tratamentos. Essas subamostras passaram pelo processo de deslintamento com ácido sulfúrico (PA), desinfestação com hipoclorito de sódio $2 \%$ por um minuto e secagem ao ar por $24 \mathrm{~h}$. Após esse processo, as sementes foram submetidas ao pré-condicionamento osmótico (restrição hídrica em ágar-água e manitol a $-1 \mathrm{MPa}$ ) por 48 horas para estimular 
o crescimento de fungos existentes nas sementes. Ao final desse período, as sementes foram secas ao ar e novamente desinfestadas com hipoclorito de sódio $2 \%$ por $30 \mathrm{~s}$. Essa segunda desinfestação teve por objetivo evitar contaminação secundária das sementes por inóculo superficial oriundo de sementes altamente contaminadas.

A transmissão do patógeno para as sementes foi analisada pelo teste de sanidade modificado de Neergaard (1979). Para esse teste, três folhas de papel de filtro foram umedecidas em água contendo 2,4-D e ágar $(2 \mathrm{~g} / \mathrm{L})$ e colocadas em placas de petri de $15 \mathrm{~cm}$ de diâmetro. Em cada placa foram acondicionadas 25 sementes, totalizando 200 sementes/tratamento. $\mathrm{O}$ teste foi conduzido em câmara de incubação com temperatura de $20 \pm 2{ }^{\circ} \mathrm{C}$ em delineamento inteiramente casualizado. Ao final do período de incubação, realizou-se a avaliação de incidência, dada em porcentagem de C. g. var. cephalosporioides em cada tratamento, e da porcentagem da semente coberta com propágulos do patógeno (PSCPP) atribuindo-se nota de 0 a 3 por semente, onde: 0 $=$ sementes sadia; $1=1$ a $10 \%$ da superfície da semente infectada; $2=11$ a $50 \%$ da superfície da semente infectada; $3=$ acima de $50 \%$ da superfície da semente infectada. Por ser facilmente confundido com Colletotrichum gossypii Southw., as estruturas de C. g. var. cephalosporioides foram cuidadosamente analisadas, utilizando a caracterização morfológica sugerida por Tanaka et al. (1996).

Os dados da incidência e da PSCPP foram correlacionados com o nível de inóculo inicial e com a intensidade da doença no campo (AACPI e AACPS) pelo método de Pearson.

\section{Análise dos dados}

As análises foram efetuadas nos programas estatísticos SAS (Statistical Analysis System) e SISVAR (Ferreira, 2000). As médias entre os tratamentos foram comparadas pelo teste de Tukey $(\mathrm{P} \leq 0,05)$. Quando não foi possível obter normalidade e homogeneidade de variância dos resíduos, os dados foram transformados para raiz de $\mathrm{x}$.

\section{RESULTADOS E DISCUSSÃO}

\section{Emergência e população final de plântulas de algodoeiro}

Não houve diferença significativa entre os tratamentos para emergência e população final (Tabela 1). Santos et al. (1993), verificaram que a presença de C. $g$. var. cephalosporioides em sementes provenientes de plantas da cultivar IAC-20 e inoculadas em diferentes estádios de desenvolvimento, não interferiu na emergência de plântulas. Pizzinatto et al. (1991) também não observaram diferenças na emergência, utilizando sementes da cultivar CNPA-3H, suscetível a ramulose, provenientes de campo inoculado com o patógeno e de campo com ocorrência natural da doença com diferentes graus de severidade.

Apesar de não haver diferença significativa entre os tratamentos para a população final, observou-se redução na porcentagem de plântulas provenientes de sementes com os níveis $8 \%$ e $16 \%$ de infecção pelo patógeno com relação aos demais tratamentos, e também nos níveis $4 \%$ e $16 \%$ quando comparados com a porcentagem de germinação (Tabela 1). Segundo Costa (1939), C. g. var. cephalosporioides pode estar relacionado ao tombamento de plântulas. Nesse trabalho, a diferença na porcentagem de plântulas pode estar relacionada à não germinação das sementes, não sendo observado tombamento, embora tenha ocorrido morte de plântulas após a primeira avaliação.

TABELA 1 - Emergência e população final de plântulas de algodoeiro com diferentes porcentagens de Colletotrichum gossypii var. cephalosporioides $(\mathrm{Cgc})$ nas sementes

\begin{tabular}{ccc}
\hline \hline $\begin{array}{c}\text { Incidência de Cgc } \\
\text { nas sementes (\%) }\end{array}$ & Emergência (\%)* & População final (\%)* \\
\hline 0 & $62 \mathrm{a}$ & $66 \mathrm{a}$ \\
4 & $76 \mathrm{a}$ & $70 \mathrm{a}$ \\
8 & $58 \mathrm{a}$ & $58 \mathrm{a}$ \\
16 & $64 \mathrm{a}$ & $56 \mathrm{a}$ \\
\hline $\mathrm{CV}(\%)$ & 10,43 & 8,60 \\
\hline
\end{tabular}

*Médias com mesma letra não diferem entre si pelo teste de Tukey ( $\mathrm{P} \leq$ $0,05)$.

\section{Área abaixo da curva de progresso da incidência (AACPI) e da severidade (AACPS) da ramulose}

Houve diferença significativa entre os tratamentos quanto à incidência (AACPI) e a severidade (AACPS) da ramulose nas plantas de algodoeiro. $\mathrm{Na}$ análise de regressão para comparar os níveis de inóculo, a AACPI e a AACPS foram maiores quanto maior a porcentagem de sementes infectadas com o patógeno (Figura 1). Resultados semelhantes foram obtidos por Machado \& Cassetari Neto (2003) em trabalho com níveis de $0 \%$ a $5 \%$ de sementes naturalmente infectadas, onde a porcentagem de plantas com sintomas iniciais da ramulose foi proporcional à incidência do fungo nas sementes. Pizzinatto et al. (1991) utilizaram sementes de plantas com notas de severidade da ramulose variando de 1 a 5 , e observaram maior porcentagem de plantas doentes em todas as avaliações, no tratamento cujas sementes apresentavam maior infecção pelo patógeno (7\%). Em outro experimento realizado no mesmo trabalho, os autores analisaram a incidência da ramulose a campo a partir de sementes de plantas inoculadas de quatro genótipos diferentes (EPAMIG 3, IAC 12-2, IAC 19 e Nu 15). Com isso, foi possível observar maior incidência da doença nos tratamentos provenientes das sementes com maior porcentagem do patógeno. Contudo, essa relação também foi atribuída à diferença genética dos materiais testados e das condições climáticas. Em trabalho realizado com o patossistema Colletotrichum lindemuthianum (Sacc. \& Magnus) Briosi \& Cavara e feijoeiro, Talamini (2003), 

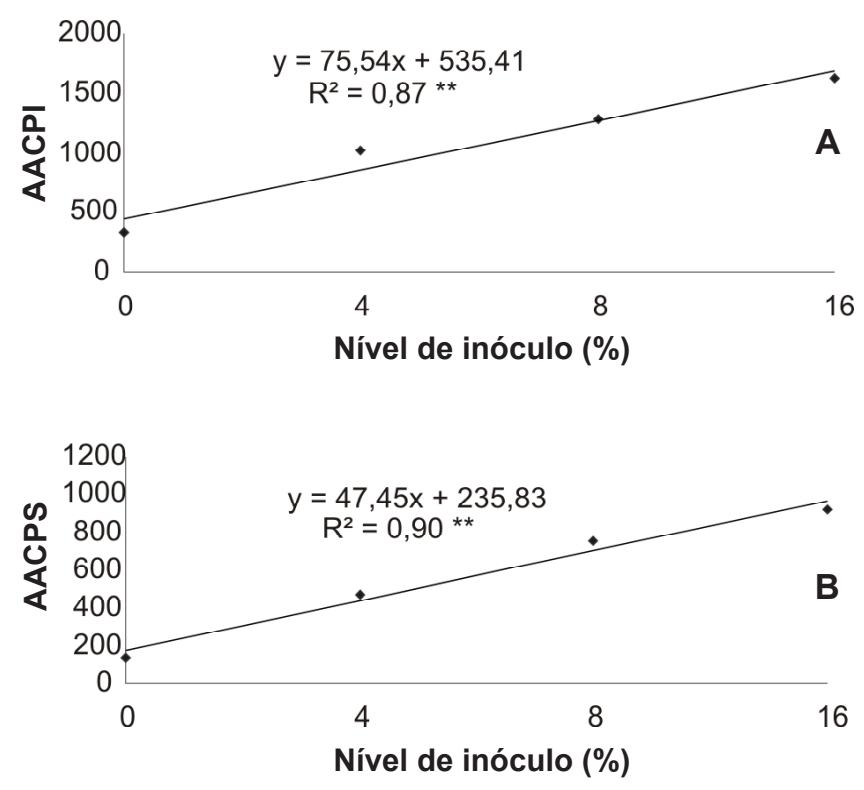

FIG. 1 - A. Área abaixo da curva de progresso da incidência (AACPI); B. e da severidade (AACPS) da ramulose; C. em função do nível de inóculo inicial de Colletotrichum gossypii var. cephalosporioides nas sementes de algodoeiro.

utilizando sementes de feijão com $0 \%, 0,5 \%, 1 \%, 2 \%$ e $4 \%$ de C. lindemuthianum inoculadas por meio da restrição hídrica, observou aumento na AACPI e na AACPS da doença com o aumento na porcentagem de sementes com o patógeno, refletindo uma tendência de maior intensidade da doença em função do inóculo inicial na semente.

\section{Transmissibilidade do patógeno planta-semente}

Houve diferença significativa entre os tratamentos quanto a incidência e a PSCPP nas sementes. Na análise de regressão realizada para comparar os níveis de inóculo, observou-se aumento da incidência e da PSCPP com o aumento no nível de inóculo inicial nas sementes (Figura 2). Comportamento semelhante foi observado nas avaliações da incidência e da severidade da doença no campo, representadas pela AACPI e AACPS. A taxa de transmissão do patógeno, planta-semente, foi de 0,36 e 0,28 para a incidência e para a PSCPP, respectivamente (Figura 2).

Foi observada correlação significativa e positiva entre o nível de inóculo inicial nas sementes com a incidência e com a PSCPP, bem como entre PSCPP e AACPS (Tabela 2). Estes resultados evidenciaram uma estreita relação entre a severidade da doença no campo e a quantidade de inóculo na superfície da semente. No entanto, em estudos realizados com algodoeiro, não há correlação entre o maior progresso da doença no campo e a presença do patógeno nas sementes. Pizzinatto et al. (1994), em estudos com diferentes genótipos, não detectaram correlação significativa entre a severidade da doença e a infecção das sementes, porém os autores não fizeram a correlação com o grau de infecção, como foi realizado nesse trabalho. Santos et al. (1993) detectaram
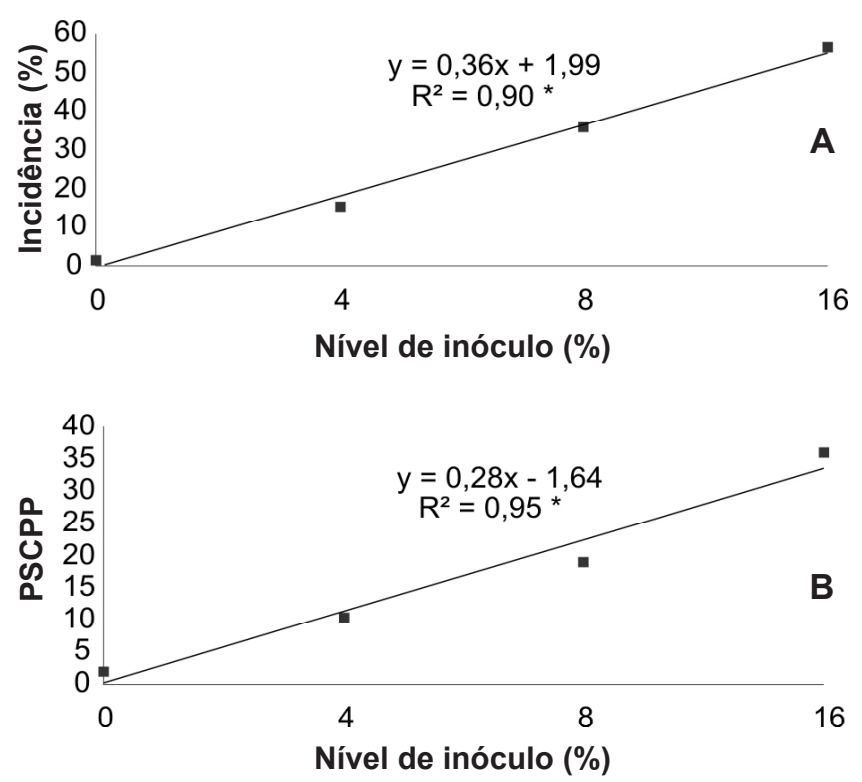

FIG. 2 - A. Influência do nível de inóculo inicial na incidência e B. porcentagem da semente coberta com propágulos (PSCPP) de Colletotrichum gossypii var. cephalosporioides, nas sementes colhidas.

TABELA 2 - Coeficiente de correlação entre a intensidade da doença no campo, o nível de inóculo e a incidência e PSCPP de Colletotrichum gossypii var. cephalosporioides nas sementes colhidas

\begin{tabular}{cccc}
\hline \hline Sanidade & AACPI & AACPS & NI \\
\hline IS & $0,83 \mathrm{~ns}$ & $0,86 \mathrm{~ns}$ & $0,91^{*}$ \\
PSCPP & $0,84 \mathrm{~ns}$ & $0,88^{*}$ & $0,88^{*}$ \\
\hline
\end{tabular}

AACPI e AACPS = área abaixo da curva de progresso da incidência e da severidade; IS e PSCPP = incidência e porcentagem da semente coberta com propágulos do patógeno; $\mathrm{NI}=$ Nível de inóculo nas sementes;

* = significativo a $5 \%$ de probabilidade; ns = não significativo.

a presença de $35 \%$ de C. g. var. cephalosporioides em sementes obtidas de plantas inoculadas no estádio de maçãs formadas. Lima et al. (1985) também chegaram a resultados semelhantes. Segundo esses autores, a inoculação realizada nesse estádio favoreceu a contaminação das sementes devido ao maior contato do patógeno com os tecidos das maçãs, sendo que o mesmo não foi observado quando as plantas foram inoculadas no estádio vegetativo da cultura, resultando em maior intensidade da doença, porém com menor incidência na semente colhida. Com esse resultado não foi possível detectar correlação positiva significativa entre a severidade da doença e a infecção das sementes.

Contudo, plantas com maior grau de severidade da ramulose podem produzir sementes com níveis maiores do patógeno. Pizzinatto et al. (1991) obtiveram maior porcentagem de sementes contaminadas quando estas foram colhidas de plantas com nota máxima na escala de severidade sugerida por Costa (1941). 
O método de inoculação utilizado nesse experimento contribuiu para a maior ocorrência do patógeno nas sementes utilizadas como inóculo inicial no campo, resultando em correlação positiva com a intensidade do patógeno nas sementes colhidas. Dessa forma, vale ressaltar que em sementes inoculadas, a ocorrência de $C$. $g$. var. cephalosporioides é superior a infecção natural (Tanaka et al., 1989).

Na avaliação da produção de algodão em caroço, não foi possível detectar diferença significativa entre os tratamentos. Apesar de se ter observado diferença na intensidade da doença no campo, essa não foi refletida nos dados de produção, no entanto, a intensidade do patógeno observada nas sementes colhidas pode representar riscos quanto à utilização dessas sementes em cultivo posterior, com prováveis perdas na produção, em áreas com clima favorável à ocorrência da doença.

\section{AGRADECIMENTOS}

À Fundação de Amparo a Pesquisa de Minas Gerais pela concessão da bolsa de estudos ao primeiro autor.

Ao Instituto Agronômico de Campinas, em especial ao pesquisador Milton Geraldo Fuzzato, pela valiosa colaboração em disponibilizar as sementes de algodoeiro da linhagem NU 15.

\section{REFERÊNCIAS BIBLIOGRÁFICAS}

CAMPBELL, C.L. \& MADDEN, L.V. Introduction to plant disease epidemiology. $1^{\text {nd }}$ ed. New York. John Wiley \& Sons Inc. 1990.

COSTA, A.S. Infestação de sementes de algodoeiro com Colletotrichum gossypii Southw. e C. gossypii var. cephalosporioides. Jornal de Agronomia 2:265-272. 1939.

COSTA, A.S. Investigação sobre a ramulose. Instituto Agronômico de Campinas (Relatório, 1012). 1941.

FERREIRA, D.F. Análises estatísticas por meio do SISVAR para Windows versão 4.0. Resumos, 45 ${ }^{\mathrm{a}}$ Reunião Anual da Região Brasileira da Sociedade Internacional de Biometria. São Carlos SP. 2000. p. 235.

KIMATI, H. Doenças do algodoeiro - Gossypium spp. In: Galli, F. (Ed.) Manual de Fitopatologia. v. 2. São Paulo. Editora Ceres, 1980. pp. 28-48.

LIMA, E.F., CARVALHO, J.M.F.C., CARVALHO, L.P \& COSTA, J.N. Transporte e transmissibilidade de Colletotrichum gossypii var. cephalosporioides através da semente do algodoeiro. Fitopatologia Brasileira 10:105-115. 1985.
MACHADO, J.C., CARVALHO, J.C.B., VIEIRA, M.G.G.C. \& GUIMARÃES, R.M. Methodology for infecting seeds by fungi using water restriction technique. Abstracts, $26^{\circ}$ International Seed Testing Congress-seed Symposium, Angers, France. 2001. p. 62.

MACHADO, A.Q. \& CASSETARI NETO, D. Nível de tolerância de Colletotrichum gossypii var. cephalosporioides em sementes de algodão no Mato Grosso. Resumos, $4^{\circ}$ Congresso Brasileiro de Algodão, Goiânia, GO. 2003.

McKINNEY, H.H. Influence of soil temperature and moisture on infection of wheat seedings by Helminthosporium sativum. Journal Agricultural Research 26:195-219. 1923.

MICHEL, B.E. \& RADCLIFFE, D. A computer program relating solute potencial to solution composition for five solutes. Agronomy Journal 87:126-130. 1995.

NEERGAARD, P. Seed pathology. London. Macmillan Press. 1979.

POZZA, E.A. \& JULIATTI, F.C. Tratamento de sementes com fungicidas no controle de doenças iniciais do algodoeiro. Fitopatologia Brasileira 19:384-389. 1994.

PIZZINATTO, M.A., CIA, E. \& FUZATTO, M.G. Transmissão de Colletotrichum gossypii var. cephalosporioides por sementes de algodoeiro. Summa Phytopathologica 17:207-217. 1991.

PIZZINATTO, M.A., CIA, E. \& FUZATTO, M.G. Relação entre a severidade de ramulose do algodoeiro em condições de campo e a presença de Colletotrichum gossypii var. cephalosporioides nas sementes produzidas. Fitopatologia Brasileira 19:50-54. 1994.

SANTOS, G.R., ZAMBOLIM, L. \& BATISTA, U.G. Transmissão de Colletotrichum gossypii var. cephalosporioides por sementes do algodoeiro em função do período de inoculação das plantas. Summa Phytopathologica 19:177-180. 1993.

TALAMINI, V. Progresso espacial e temporal da antracnose a partir de diferentes níveis de inóculo inicial em sementes de feijoeiro. (Tese de Doutorado). Lavras. Universidade Federal de Lavras. 2003.

TANAKA, M.A.S. \& MACHADO, J.C. Patologia de sementes. Informe Agropecuário 11:40-46. 1985.

TANAKA, M.A.S., MARIANO, M.I.A. \& MENTEN, J.O.M. Inoculação artificial de sementes de algodão com Colletotrichum gossypii var. cephalosporioides e infecção das sementes em função do tempo de exposição ao patógeno. Summa Phytopathology 15:232-237. 1989

TANAKA, M.A.S. \& MENTEN, J.O.M. Relação entre a resistência do algodoeiro à ramulose e a transmissão de Colletotrichum gossypii var. cephalosporioides pelas sementes. Summa Phytopathologica 18:227-234. 1992.

TANAKA, M.A.S., MENTEN, J.O.M. \& MACHADO, J.C. Hábito de crescimento de Colletotrichum gossypii e C. gossypii var. cephalosporioides em sementes de algodoeiro. Bragantia 55:95104. 1996. 